\title{
Gene copy number variation in natural populations of Plasmodium falciparum in Eastern Africa
}

Joan Simam ${ }^{7}$, Martin Rono ${ }^{1,4,8}$, Joyce Ngoi ${ }^{1}$, Mary Nyonda ${ }^{2}$, Sachel Mok ${ }^{3}$, Kevin Marsh ${ }^{4}$, Zbynek Bozdech ${ }^{5}$ and Margaret Mackinnon ${ }^{6^{*}}$

\begin{abstract}
Background: Gene copy number variants (CNVs), which consist of deletions and amplifications of single or sets of contiguous genes, contribute to the great diversity in the Plasmodium falciparum genome. In vitro studies in the laboratory have revealed their important role in parasite fitness phenotypes such as red cell invasion, transmissibility and cytoadherence. Studies of natural parasite populations indicate that CNVs are also common in the field and thus may facilitate adaptation of the parasite to its local environment.

Results: In a survey of 183 fresh field isolates from three populations in Eastern Africa with different malaria transmission intensities, we identified 94 CNV loci using microarrays. All CNVs had low population frequencies (minor allele frequency $<5 \%$ ) but each parasite isolate carried an average of 8 CNVs. Nine CNVs showed high levels of population differentiation ( $F_{S T}>0.3$ ) and nine exhibited significant clines in population frequency across a gradient in transmission intensity. The clearest example of this was a large deletion on chromosome 9 previously reported only in laboratory-adapted isolates. This deletion was present in 33\% of isolates from a population with low and highly seasonal malaria transmission, and in $<9 \%$ of isolates from populations with higher transmission. Subsets of CNVs were strongly correlated in their population frequencies, implying co-selection.
\end{abstract}

Conclusions: These results support the hypothesis that CNVs are the target of selection in natural populations of $P$. falciparum. Their environment-specific patterns observed here imply an important role for them in conferring adaptability to the parasite thus enabling it to persist in its highly diverse ecological environment.

Keywords: Copy number variation, Plasmodium falciparum, Adaptation

\section{Background}

P. falciparum, the most virulent of the species that cause malaria in humans, is characterized by extensive genetic diversity that enables the parasite to escape host immune defence, resist antimalarial drugs and pose a further challenge to vaccine development [1-4]. Sources of genomic variation in this parasite range from changes at the single nucleotide level through to large structural alterations of the chromosomes. Gene copy number vari-

\footnotetext{
* Correspondence: mmackinnon.mackinnon@gmail.com

${ }^{6}$ http://www.researcherid.com/rid/L-3155-2013

Full list of author information is available at the end of the article
}

ants (CNVs) lie between these extremes, consisting of deletions and amplifications of a gene or set of contiguous genes. CNVs are thought to directly affect the level of gene expression through altering gene dosage, but also indirectly through modification of the chromatin environment in the vicinity of the CNV (reviewed in [5]). Potentially, therefore, CNVs may influence clinically relevant parasite phenotypes such as drug resistance, erythrocyte invasion and transmissibility.

Interest in CNVs in malaria parasites has been driven by confirmation of their role in adaptation, evolution and disease in other organisms [6-9], boosted by advances in technologies for high-throughput genome-

(c) The Author(s). 2018 Open Access This article is distributed under the terms of the Creative Commons Attribution 4.0 International License (http://creativecommons.org/licenses/by/4.0/), which permits unrestricted use, distribution, and reproduction in any medium, provided you give appropriate credit to the original author(s) and the source, provide a link to the Creative Commons license, and indicate if changes were made. The Creative Commons Public Domain Dedication waiver (http://creativecommons.org/publicdomain/zero/1.0/) applies to the data made available in this article, unless otherwise stated. 
wide scans of the malaria genome [10]. Surveys of parasite lines adapted to in vitro culture conditions in the laboratory, both long-term [11-17] and short-term [18], have revealed many CNVs in the P. falciparum genome. Common among these are two large deletions that abrogate traits which are crucial to survival in vivo but dispensable in vitro. These are the deletion of a region on chromosome 9 that contains several genes required for formation of gametocytes, the life stage required for transmission to new hosts via mosquitoes $[19,20]$, and a region on chromosome 2 containing a gene encoding the knob associated histidine rich protein (KAHRP) that mediates binding of the infected red blood cell to other host cells (cytoadherence) thereby allowing the parasite to avoid circulation through the spleen where it would otherwise be destroyed [21]. Another example of an in vitro-associated $\mathrm{CNV}$ is the amplification of reticulocyte-binding protein 1 encoding gene $(r h 1)$ [12, $16,18,22]$. This protein is involved in red cell invasion [23] and appears to be associated with increased parasite asexual replication rate in vitro $[16,22]$. In vitro selection for drug resistance has uncovered further CNVs. Examples include amplification of genes encoding multidrug resistance protein 1 (Pfmdr1) that associates with resistance to multiple drugs in in vitro studies [24]; amplifications in the genes encoding the cysteine proteases falcipain 2 (FP2a and $F P 2 b)$ and falcipain 3 (FP3) in which mutations have been associated with resistance to the antimalarial compound artemisinin [25], and which help breakdown haemoglobin in the food vacuole [26], a process that is required for artemisinin to be effective [27]; a deletion of 15 consecutive genes on chromosome 10 in parasites bearing mutations in the chloroquine resistance transporter gene $(P f c r t)$ [28]; deletion of 23 adjacent genes in chromosome 14 in strains resistant to the anti-malarial compound, fosmidomycin [13]; and amplification of the gene encoding GTP cyclohydrolase 1 (gch1) [12, 18], an enzyme high in the folate synthesis pathway and thus a potential target for the antifolate class of anti-malarial drugs. Most of these laboratoryderived CNVs have been shown to affect expression levels of genes inside the $\mathrm{CNV}$ and, in a few cases, genes located on other chromosomes $[18,28]$. Combined, the evidence from in vitro studies strongly supports the hypothesis that CNVs play an important role in parasite adaptation to novel environments.

The relevance of in vitro-based studies of CNVs to parasite adaptation in the field remains unclear, however. For example, the cytoadherence and gametocyte-linked deletions on chromosome 2 and 9, and the replicationlinked $r h 1$ amplification have not been found among the limited number of field isolates of $P$. falciparum surveyed to date [22, 29]. This implies strong selection against these mutations in vivo. On the other hand,
CNVs involving drug resistance have been observed in the field, e.g., amplifications in $m d r 1$ in patients with failed response to drugs [30], and gch1 amplification in populations subjected to antifolate drug pressure [31, $32]$, thus reflecting their adaptive value under field conditions if there are novel selection forces at play. Many CNVs not observed among laboratory isolates and of unknown clinical or adaptive significance have been discovered in global surveys of field populations [29]. Indeed, it is estimated that between $0.3-6 \%$ of the parasite's genome is subject to variation in gene copy number. This is greater than the fraction represented by single nucleotide polymorphisms (SNPs).

Thus the evidence to date suggests that CNVs play a significant role in adaptation of the parasite to novel environmental conditions. Whether this includes naturally varying factors such as immunity, mosquito density and host genetics, as distinct from selective agents not previously encountered such as drugs, remains unknown. Here, we test the hypothesis that CNVs provide the source of adaptive variation used by the parasite to evolve in response to natural environmental variation. Empirical support for this hypothesis would have implications for malaria control programmes that change the epidemiological setting of the parasite. We examine this hypothesis by analysing CNV variation among geographically and temporally separated populations of $P$. falciparum in Eastern Africa that differ widely in malaria transmission intensity and thus related selection pressures. We further test for experimental sources of variation in the detectability of CNVs in order to account for or rule out experimental bias in our results.

\section{Results and discussion}

\section{General properties of CNVs}

From 183 P. falciparum infected blood samples (Table 1), using a microarray previously validated for $\mathrm{CNV}$ detection [18] and after applying stringent CNV definition criteria, a total of 94 different $\mathrm{CNVs}$ with minor allele frequency (MAF) greater than 2.2\% (i.e., found in 4 or more samples), and containing 228 different genes, were detected (Additional file 1). Thirty-one of these were classed as deletions, 58 as amplifications and 5 as carrying both types of alleles ("amp-dels"). These classifications were made in reference to the P4 isolate [18] with one exception, namely, cnv9_269 for which P4 carried a deletion: in this case, the deletion was defined with respect to the majority of isolates in the sample population.

$\mathrm{CNVs}$ were distributed throughout the 14 chromosomes of the parasite's nuclear genome (Fig. 1a). CNVs varied in size from $400 \mathrm{bp}$ to $90 \mathrm{~kb}$ (Fig. 1b). The majority of CNVs contained less than 3 genes 
Table 1 Characteristics of the four study populations

\begin{tabular}{|c|c|c|c|c|}
\hline Population & Kisumu & Kilifi pre malaria decline & Kilifi post malaria decline & Sudan \\
\hline Malaria transmission intensity & High & Medium-high & Medium-low & Low \\
\hline Number of samples & 49 & 33 & 49 & 52 \\
\hline Year of sample collection & 2008 & 1994-1996 & 2010 & 2007 \\
\hline Median age in months & 36 & 30 & 53.5 & 84 \\
\hline (range) & $(6-72)$ & $(11-37)$ & $(14-147)$ & $(12-612)$ \\
\hline $\log _{10}$ median parasitaemia & 5.3 & 4.7 & 5.1 & 5.1 \\
\hline 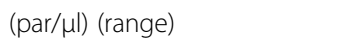 & $(4.9-5.8)$ & $(4.0-5.8)$ & $(2.5-6.1)$ & $(4.4-5.8)$ \\
\hline Median hemoglobin (g/dl) & 9.9 & 9.4 & 10.6 & 9.6 \\
\hline (range) & $(5.2-15.2)$ & $(5.3-13.2)$ & $(3.4-12.1)$ & $(3.2-12.9$ \\
\hline Median number of clones & 2 & 2 & 2 & 2 \\
\hline (range) & $(1-6)$ & $(1-7)$ & $(1-5)$ & $(1-5)$ \\
\hline $\begin{array}{l}\text { Monoclonal infections } \\
\text { (percentage) }\end{array}$ & 10.2 & 33.3 & 18.4 & 26.9 \\
\hline
\end{tabular}

a

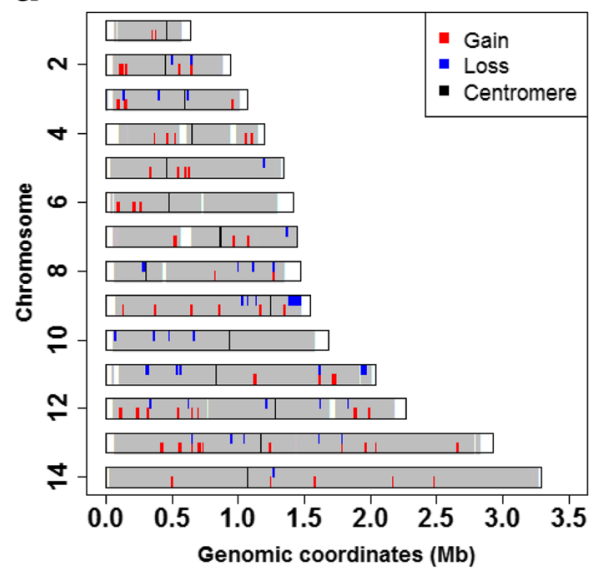

C

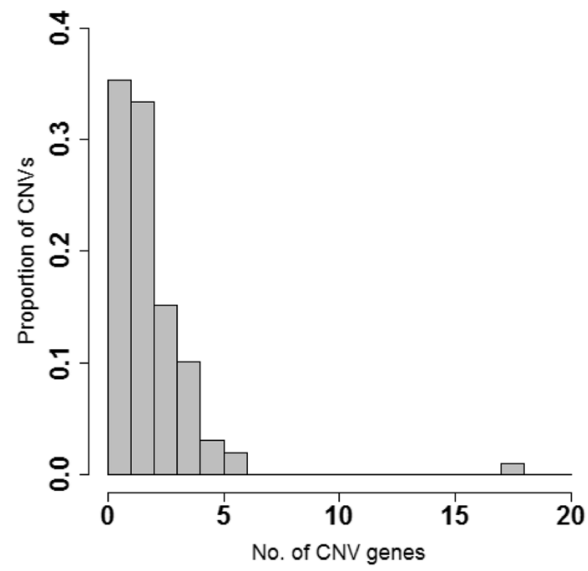

b

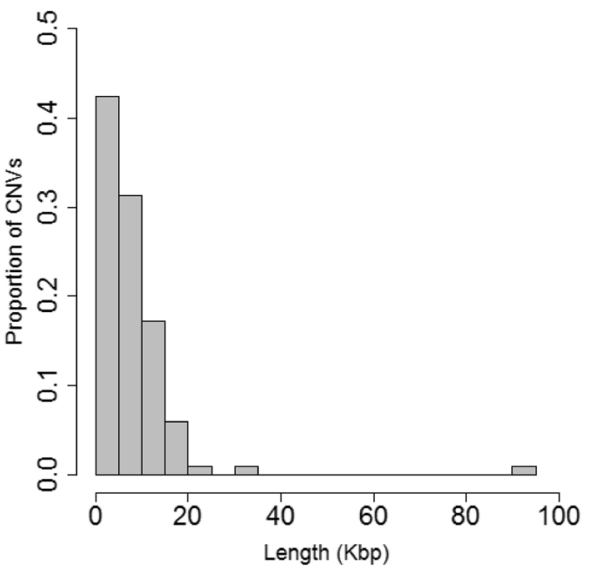

d

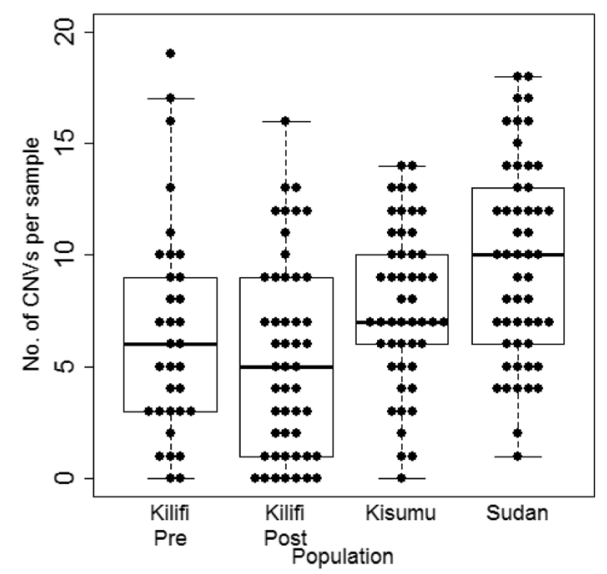

Fig. 1 Location and properties of CNVs in the P. falciparum genome. a Chromosomal location of the 94 CNVs in the 14 nuclear chromosomes of the P. falciparum genome (deletions in blue and amplifications in red). White vertical bars represent regions not targeted by the microarray probes. Black vertical bars are locations of centromeres. Distributions of length of CNVs (b), number of genes per CNV (c) and number of CNVs per sample (d) split by study population (horizontal line, median number; top and bottom boundaries, 75th and 25th percentiles; whiskers, minimum and maximum) 
(median of 2) with the largest $\mathrm{CNV}$ on chromosome 9 consisting of 18 genes (Fig. 1c). The number of CNVs per sample ranged from 0 to 19 with an average of $8 \mathrm{CNVs}$ per isolate (Fig. 1d) The summed length of all $\mathrm{CNVs}$ identified here was $786.7 \mathrm{kbp}$ which represents $3.4 \%$ of the parasite genome and approximately $4.5 \%$ of genes in the genome. Twenty of the $94 \mathrm{CNVs}$ detected here (21\%) have been reported in previous studies (Additional file 1), albeit with different breakpoints in some cases: thus the majority of CNVs identified here are novel. Nonetheless, these results accord with previous studies showing considerable amounts of standing variation in CNV loci in field populations $[16,29]$ and thus support the hypothesis that CNVs play an adaptive role in natural populations of $P$. falciparum.

\section{Systematic effects on general CNV prevalence}

Most CNVs had low population frequencies (<5\%, Fig. 2). There were no significant effects of multiplicity of infection (MOI), parasitaemia and patient characteristics (age and haemoglobin), or two-way interactions between these factors, on the population prevalence of CNVs overall $(P>0.05$ by F-test, Fig. 2a). This rules out possible bias in detectability of CNVs due to 'dilution' in the case of MOI, and total DNA concentration effects in the case of parasitaemia. By contrast, study population was a strong determinant of overall $\mathrm{CNV}$ prevalence $(P<0.001)$, with overall lower prevalence in the medium transmission populations (Kilifi) than in the high and low transmission populations $(P=0.35$ fitting a linear covariate for transmission intensity, Fig. 2a). Thus population differences in CNV prevalence were not due to bias in detectability caused by sample processing or infection and host-related factors.

Properties of the genes contained within the CNVs and their encoded proteins did not, in general, relate to the probability of being copy number variable. Exceptions to this were as follows: amplification CNVs were more likely to occur in genes that had maximum expression levels during the rings and trophozoite stages within the $48 \mathrm{~h}$ replication cycle $(P=0.02$ by likelihood ratio test, Fig. $2 \mathrm{~b}$ ); deletion CNVs were more prevalent in genes with high asexual:sexual stage expression ratios $(P=0.02$, Fig. 2c); and there was a significant, but not unidirectional, effect of SNP density on the prevalence of deletion CNVs $(P=0.02)$.

Seven of 255 functional categories of genes were highly significantly enriched for genes belonging to CNVs, five of them for deletion CNVs (nominal $P<0.01$ by hypergeometric test, only two of which were significant $(P<0.05)$ after accounting for multiple testing (Table 2). Enriched pathways included those involved in export of proteins to the surface of infected red blood cells, and in core metabolic processes such as glycolysis, intracellular trafficking and transcriptional regulation (Table 2). These results indicate that CNVs are not confined to non-essential, non-central processes, as might be expected if the alterations in gene copy number led to dramatic, irreversible changes to gene expression levels.

\section{Evidence of population-specific adaptation}

Many CNVs (28 of 99 when defining amp-dels as two separate $\mathrm{CNVs}$ ) were present in all four populations and a few (12/99) were exclusive to single populations (Fig. 3a). Mean $\mathrm{F}_{\mathrm{ST}}$ values ranged between 0.02 and 0.11 across the 6 pairwise population comparisons (Fig. 3c) which are typical values of background population differentiation in $P$. falciparum based on SNPs [33]. However, nine CNVs (9\%) had pairwise $\mathrm{F}_{\mathrm{ST}}$ values greater than the arbitrary significance threshold of 0.3 , equivalent to the top $3 \%$ of all population pairwise values (Fig. 3c). These were thus declared as potential targets of population-specific selection (Table 3).

A higher than expected number of CNVs showed significant transmission intensity-related clines in population frequency $(P<0.001$ based on the distribution of the global test statistic from permuted data, Table 3, Fig. 3b). Nine CNVs (9\%, 4 amplifications and 5 deletions) showed individual significance after adjustment for multiple testing (Benjamini-Hochberg adjusted $P<0.05$ ). All of these CNVs decreased in frequency as transmission intensity increased (Table 3). One of these was the large deletion on the right arm of chromosome 9 (cnv9_269) that has previously been observed only in laboratory-adapted isolates $[11,12,16,18,19,34]$. A further seven CNVs (6 with negative clines, 2 of which were deletions) had marginally significant frequency clines (adjusted $P<0.10$ ). There was strong overlap in the CNVs displaying population differentiation by $\mathrm{F}_{\mathrm{ST}}$ and those exhibiting transmission-related clines (Table 3).

These results strengthen the argument that CNVs play a role in local adaptation of $P$. falciparum to its natural environment. Our results suggest that a 'landscape genomics' approach applied to malaria parasite populations on a much larger scale than in this study might accelerate progress towards identification of genetic variants that enable the parasite to survive and thrive in its highly variable environment. Such an approach has been demonstrated as successful in identifying adaptive genes in humans affecting metabolic disease due to diet, altitude and heat $[35,36]$ and infectious diseases such as malaria [37].

\section{The chromosome 9 deletion}

The most striking transmission-related frequency cline was in cnv9_269 which was found most often in Sudan (17 out of 52 isolates, 33\%), but at low frequency in other populations $(<9 \%)$. Its reported absence from 


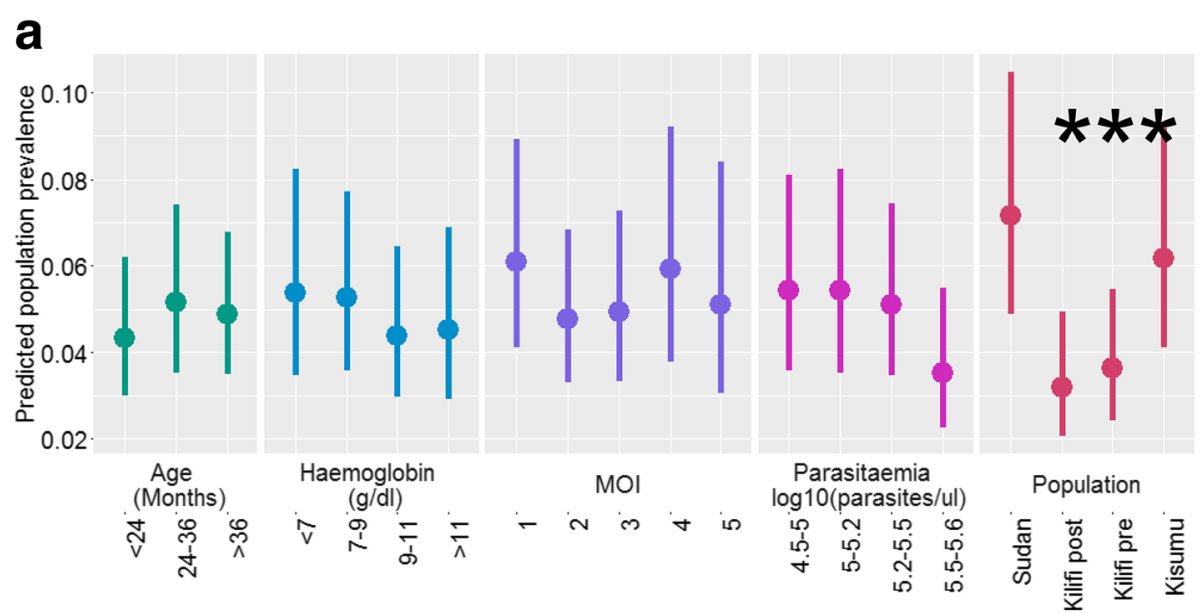

b

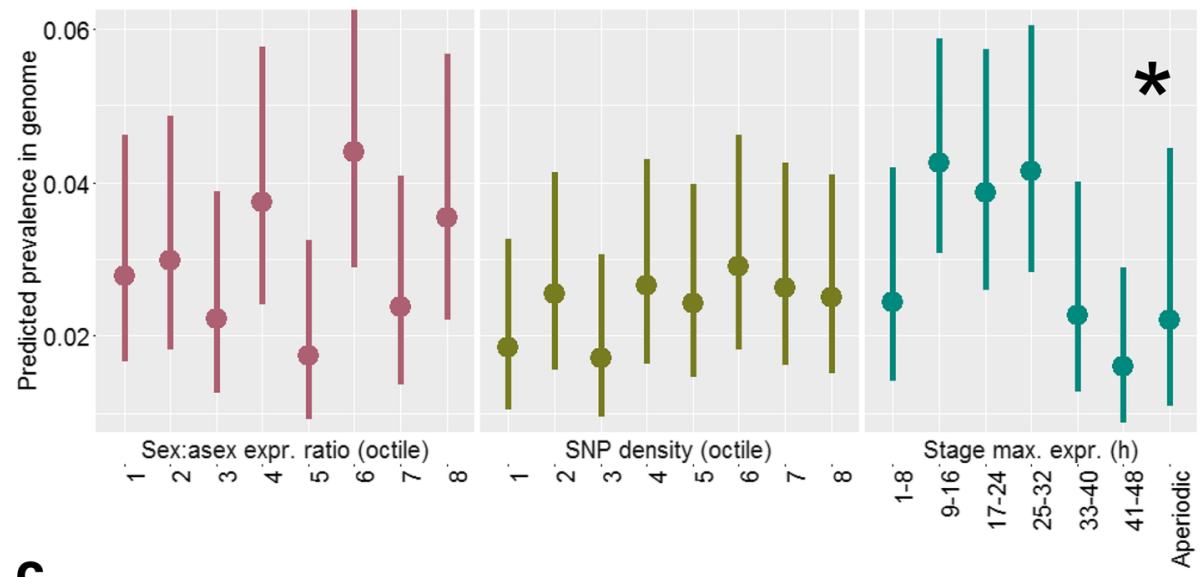

\section{C}

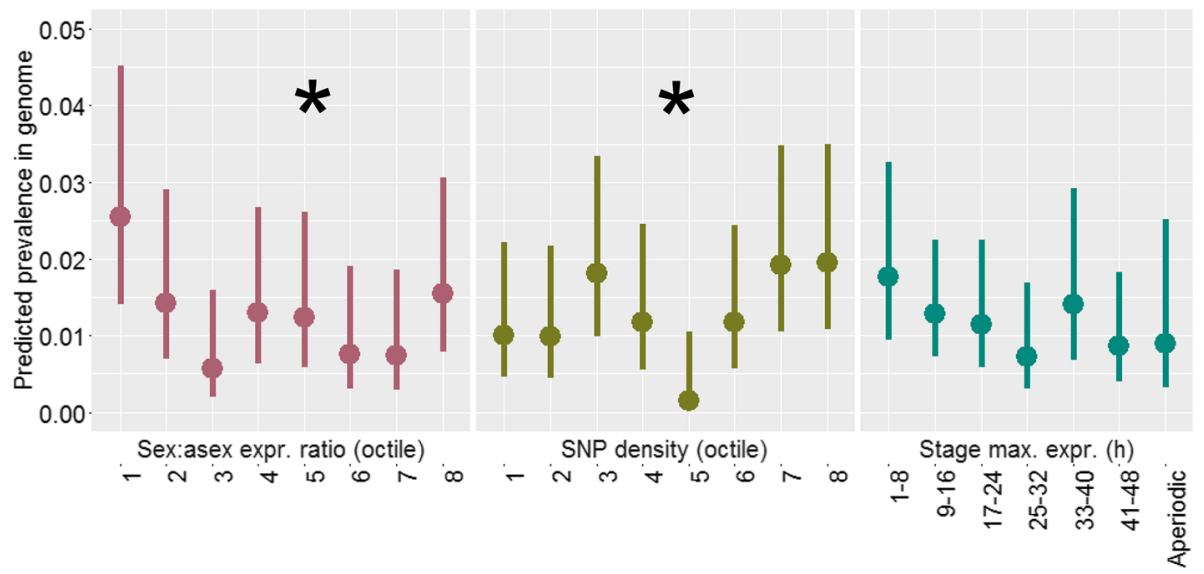

Fig. 2 Systematic effects of host, parasite and gene factors on overall CNV prevalence. a Effects of host status, infection status and population on population prevalence of all CNVs. $\mathbf{b}$ Effects of gene properties on genomic prevalence of amplification CNVs. $\mathbf{c}$ As for b but for deletion CNVs. Points show least-squares means for each level of the factors ( $x$-axis) adjusted for other factors in the model (separate panels). Vertical lines show upper and lower 95\% confidence intervals. Significance of each factor is indicated at the top of each panel. ${ }^{*}, P<0.05 ;{ }^{* *}, P<0.001$

isolates taken directly from patients in previous studies has led to the interpretation that this deletion is an artefact of in vitro culture, assumed to arise from a replication advantage under these novel conditions, but strongly selected against in nature because it contains genes coding for several proteins essential for early gametocyte development $[38,39]$ and thus transmission. The deleted region also contains genes encoding proteins 
Table 2 Functional gene categories showing significant enrichment for CNVs

\begin{tabular}{|c|c|c|c|c|}
\hline Functional gene set & $\begin{array}{l}\text { No. of genes } \\
\text { in CNVs }\end{array}$ & $\begin{array}{l}\text { Total no. of genes } \\
\text { in gene set }\end{array}$ & $\begin{array}{l}\text { Nominal } \\
\text { P-value }^{\text {a }}\end{array}$ & $\begin{array}{l}\text { Adjustec } \\
P \text {-value }\end{array}$ \\
\hline \multicolumn{5}{|l|}{ Deletions } \\
\hline Exported proteins - PHISTs & 8 & 48 & $<0.001$ & $<0.001$ \\
\hline $\begin{array}{l}\text { Characteristics of Plasmodium falciparum } \\
\text { export proteins that remodel infected } \\
\text { erythrocyte }\end{array}$ & 5 & 35 & $<0.001$ & 0.043 \\
\hline Glycolysis & 4 & 27 & 0.001 & 0.10 \\
\hline Exported proteins - Unique & 6 & 72 & 0.0025 & 0.10 \\
\hline Utilization of phospholipids & 4 & 40 & 0.005 & 0.26 \\
\hline \multicolumn{5}{|l|}{ Amplifications } \\
\hline $\begin{array}{l}\text { Rab and other proteins involved in } \\
\text { intracellular traffic }\end{array}$ & 3 & 14 & 0.009 & 1 \\
\hline RNA binding genes & 12 & 173 & 0.01 & 1 \\
\hline
\end{tabular}

${ }^{\mathrm{B} B y}$ hypergeometric test without adjustment for testing of multiple gene sets

${ }^{\mathrm{b}}$ Adjusted for multiple-testing by the Benjamini-Hochberg method

\section{a}

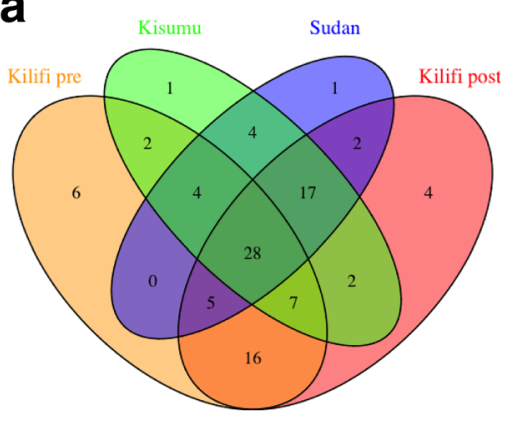

C

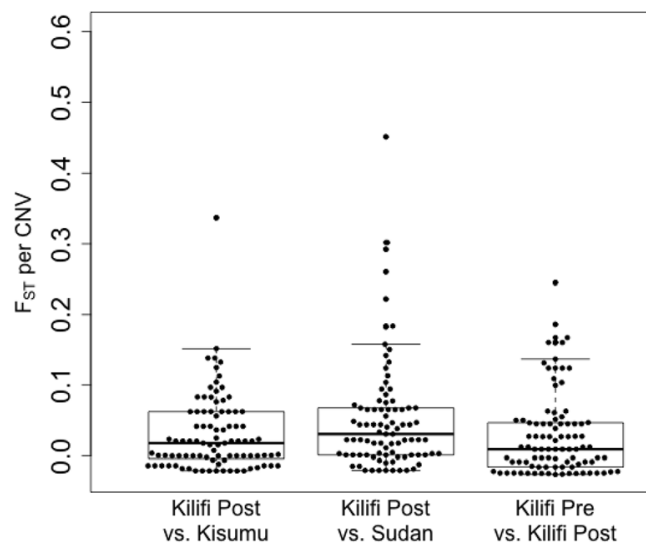

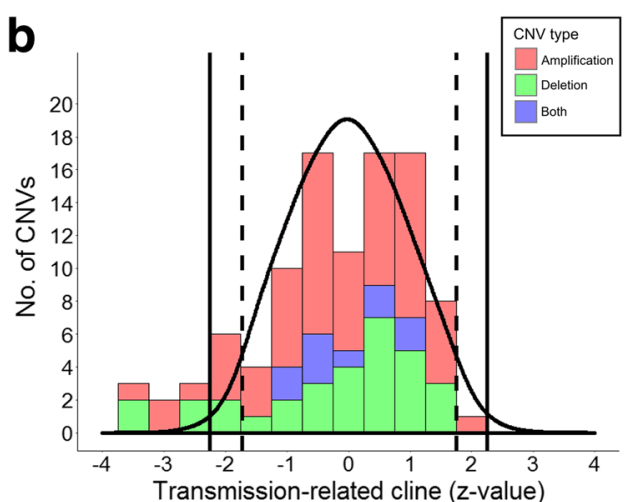

Transmission-related cline (z-value)

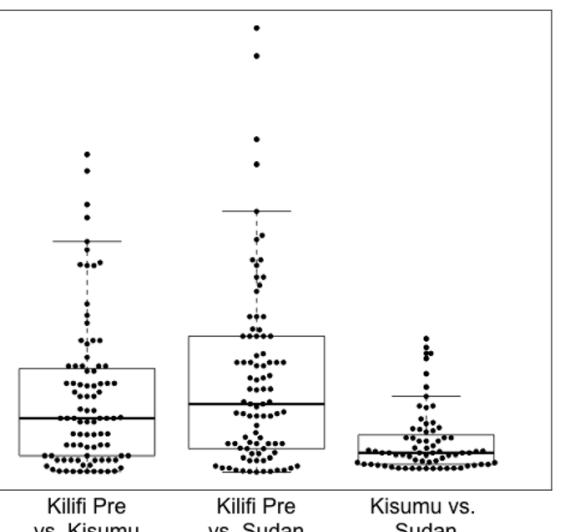

Fig. 3 Population differentiation of CNVs. a Overlap of CNVs between populations. b Distribution of transmission intensity-related frequency clines (z-score) among the CNVs (filled bars, red for amplifications, green for deletions) vs. the expected distribution based on permuted data (black line). Vertical solid lines indicate the upper and lower $2.5 \%$ probability thresholds of the latter. Vertical dashed lines indicate the equivalent thresholds

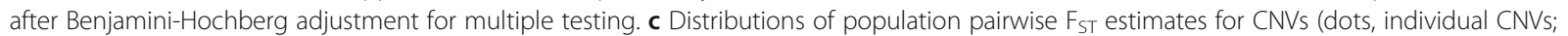
horizontal line, median number; top and bottom boundaries, 75th and 25th percentiles, whiskers, minimum and maximum) 
Table 3 CNVs showing evidence of population-specific adaptation. Only those CNVs that either had Fst greater than 0.30 or which showed significant transmission intensity-related clines in population frequency are shown

\begin{tabular}{|c|c|c|c|c|}
\hline CNV name & CNV type & $\mathrm{F}_{S T}{ }^{a}$ & Cline $^{b}$ & Annotations $^{c}$ \\
\hline cnv5_101 & Amplification & 0.64 & $-* * *$ & 6-cysteine protein (P38) SET domain protein, putative (SET9) \\
\hline cnv12_413 & Amplification & 0.64 & $-*$ & \\
\hline cnv9_242 & Amplification & 0.44 & & P1 nuclease, putative \\
\hline cnv13_478 & Deletion & 0.46 & $-\dagger$ & E1-E2 ATPase, putative \\
\hline cnv9_254 & Deletion & 0.41 & & $\begin{array}{l}\text { protein phosphatase-beta thioredoxin-like protein } 2 \text { (TLP2) zinc } \\
\text { binding protein (Yippee), putative histone deacetylase } 1 \text { (HDAC1) }\end{array}$ \\
\hline cnv3_051 & Amplification & 0.34 & & circumsporozoite- and TRAP-related protein (CTRP) \\
\hline \multirow[t]{3}{*}{ cnv3_036 } & Amplification & 0.32 & $-\dagger$ & Plasmodium exported protein (hyp1), unknown function (GEXP21) \\
\hline & & & & Plasmodium exported protein, unknown function \\
\hline & & & & Plasmodium exported protein, unknown function \\
\hline cnv6_129 & Deletion & 0.30 & & $\begin{array}{l}\text { ubiquitin-conjugating enzyme E2, putative polypyrimidine tract binding } \\
\text { protein, putative }\end{array}$ \\
\hline cnv4_078 & Amplification & 0.30 & $-\dagger$ & \\
\hline \multirow[t]{3}{*}{ cnv11_354 } & Deletion & 0.27 & & Plasmodium exported protein (PHISTc), unknown function (GEXP12) \\
\hline & & & & Plasmodium exported protein (hyp11), unknown function \\
\hline & & & & Plasmodium exported protein, unknown function \\
\hline cnv11_355 & Deletion & 0.18 & $-* * *$ & antigen 332, DBL-like protein (Pf332) \\
\hline \multirow[t]{17}{*}{ cnv9_269 } & Deletion & 0.27 & $--^{* * *}$ & gametocyte development protein 1 (GDV1) \\
\hline & & & & Plasmodium exported protein, unknown function (GEXP22) \\
\hline & & & & gametocytogenesis-implicated protein (GIG) \\
\hline & & & & Plasmodium exported protein, unknown function \\
\hline & & & & cytoadherence linked asexual protein 9 (CLAG9) \\
\hline & & & & ring-exported protein 1 (REX1) \\
\hline & & & & ring-exported protein 2 (REX2) \\
\hline & & & & early transcribed membrane protein (ETRAMP9) \\
\hline & & & & ring-exported protein 4 (REX4) \\
\hline & & & & virulence-associated protein 1 (VAP1) \\
\hline & & & & Plasmodium exported protein (PHISTc), unknown function \\
\hline & & & & (GEXP05) \\
\hline & & & & lysophospholipase, putative \\
\hline & & & & Plasmodium exported protein (PHISTc), unknown function \\
\hline & & & & Plasmodium exported protein (PHISTb), unknown function \\
\hline & & & & Plasmodium exported protein, unknown function \\
\hline & & & & lysophospholipase, putative \\
\hline cnv1_007 & Amplification & 0.26 & $--^{* *}$ & tubulin-specific chaperone a, putative N-acetyltransferase, putative \\
\hline cnv14_549 & Amplification & 0.21 & $-* * *$ & thioredoxin peroxidase 1 (Trx-Px1) copper transporter \\
\hline cnv11_355 & Deletion & 0.18 & $-* * *$ & antigen 332-DBL-like protein (Pf332) \\
\hline cnv2_023 & Deletion & 0.14 & $-*$ & conserved Plasmodium membrane protein, unknown function \\
\hline cnv12_368 & Deletion & 0.07 & $-^{*}$ & glycerol-3-phosphate dehydrogenase, putative \\
\hline
\end{tabular}

${ }^{\mathrm{a}}$ Maximum of pairwise population $\mathrm{F}_{\mathrm{ST}}$ values

${ }^{\mathrm{b}}$ Significance of transmission intensity cline in CNV frequency after Benjamini-Hochberg correction for multiple testing. (†, $P<0.10 ;{ }^{*}, P<0.05$; $^{* *}, P<0.01 ;{ }^{* * *}, P<$ $0.001 ;+$, positive association; - , negative association). Four further CNVs had clines with adjusted $P<0.10$ but $\mathrm{F}_{\mathrm{ST}}<0.3$ and so are not shown (three amplifications, cnv9_262, - †; cnv5_109, + †; cnv14_573, - †, and one deletion, cnv7_193,- †)

'Excluding genes with no known or putative function 
involved in cytoadherence [40], the in vivo process by which parasite-infected red cells adhere to vascular tissues and thereby protect parasite infected red cells from being circulated and destroyed by the spleen. Since cytoadherence is redundant in vitro, selection against this deletion would only be expected to occur in vivo, just as for gametocyte development genes. A replication advantage of this deletion in vitro might arise from the lower metabolic cost of DNA replication of a smaller genome. Alternatively, it may arise because the production of gametocytes imposes a cost on asexual replication [41]. These advantages would also be expected to apply in vivo.

We envisage two possible mechanisms for how this deletion could be maintained in natural populations despite its apparent cost to transmission and survival of host clearance mechanisms, and for why these may be more powerful in areas with low or strongly seasonal transmission intensities. First, the mutation may commonly arise de novo in new infections, rising to high within-host frequency due to a replication advantage, but ultimately being unable to transmit. Such 'shortsighted, dead-end' within-host evolution has been invoked to explain the high virulence of some pathogens [42]. In Plasmodium, such a scenario would be favoured when there are long mosquito-free periods between malaria transmission seasons, as occur in the eastern Sudan population examined here, because there is no transmission cost to counteract the short-term selection for rapid replication.

An alternative explanation is that genomes with inherent instability at the chromosome 9 locus are maintained in natural parasite populations through 'bet hedging'. Under this scenario, within a host, a subset of asexual lineages deriving from the same parasite clone may carry the deletion while simultaneously maintaining intact lineages that are capable of transmitting. A bet-hedging strategy would be selectively favoured when there is no competition from co-infecting genotypes for uptake by the mosquito. It would also require that kin selection was at play, as appears to be the case for sex ratio adjustment by Plasmodium in response to the presence of unrelated genotypes [43].

Both these explanations are consistent with the high frequency of cnv9_269 in the highly seasonal setting of Sudan observed here. This observation also accords with the finding in two populations in west Africa of extreme $\mathrm{F}_{\mathrm{ST}}$ values for five SNPs within and adjacent to the first gene in cnv9_269 ( $g d v 1$, encoding gametocyte development protein1, PF3D7_0935400). In this case, the minor allele was found more often in the population with strong malaria seasonality than in the population with year-round transmission [44], consistent with this study. Thus there is mounting evidence that this locus is the target of selection in highly seasonal and low transmission environments.

It seems likely that the cnv9_269 deletion has escaped detection in field isolates until now because for most detection methods, including $\mathrm{CGH}$, its presence would be masked by non-deleted genomes in the parasite population in the blood. This masking effect would be strongest in high transmission areas where most infections are multi-clonal, and thus may have contributed to the observed negative frequency cline in cnv9_269 and other deletions found in this study.

\section{Associations between CNVs}

Linkage disequilibrium analyses revealed three distinct sets of CNVs (Blocks 1 to 3 ) with strong populationlevel associations between them $(0.6<r<-0.4)$ (Fig. 4a). The largest block (Block 3) contained approximately equal numbers of amplification and deletion CNVs which, respectively, typically contained genes with high and low sexual stage expression levels (Fig. 4b), and thus are denoted as 'sexual stage CNVs' here. There was a striking negative correlation between Block $3 \mathrm{CNV}$ s and a deletion CNV that was not a member of any block, cnv9 254. The latter contains a gene encoding histone deacetylase 1 (HDAC1) which has been strongly implicated as the provider of epigenetic silencing that underpins the transcriptional programme of the intraerythrocytic $48 \mathrm{~h}$ asexual replication cycle and which appears to be switched off upon conversion to gametocytes [45]. Block $3 \mathrm{CNVs}$ further showed a strong positive association with another deletion on chromosome 9, cnv9_259, which contains a gene encoding a component of cytochrome oxidase, an enzyme used in the energy-generating electron transport chain in the mitochondrion. Malaria parasites increase their dependence on mitochondrial activity upon conversion to gametocytes [46, 47]. Combined, the data suggest that cnv9_254 and cnv9_259 deletions, in conjunction with Block $3 \mathrm{CNVs}$, are involved in up-regulation of sexual stage activities.

This contrasts with Block $1 \mathrm{CNVs}$ which associated with loss of sexual function and perhaps gain in asexual function. Block 1 contains cnv9_269, the chromosome 9 deletion causing loss of gametocyte production discussed above, and another deletion, cnv11_355, which, as for cnv9_269, contains a gene involved in export of proteins to the red cell surface, Pf332 [48]. Block 1 also includes a CNV on chromosome 2, cnv2_013, which, like cnv9 269 , is frequently found in laboratory isolates adapted to in vitro culture. However, this $\mathrm{CNV}$ was amplified in field parasites, whereas in vitro, only deleted forms are found. cnv2_013 contains genes encoding KAHRP and PTP1, both of which are involved in export to the red cell surface and cytoadherence in asexual blood stage parasites $[49,50]$, and LSAP2, which is associated with 

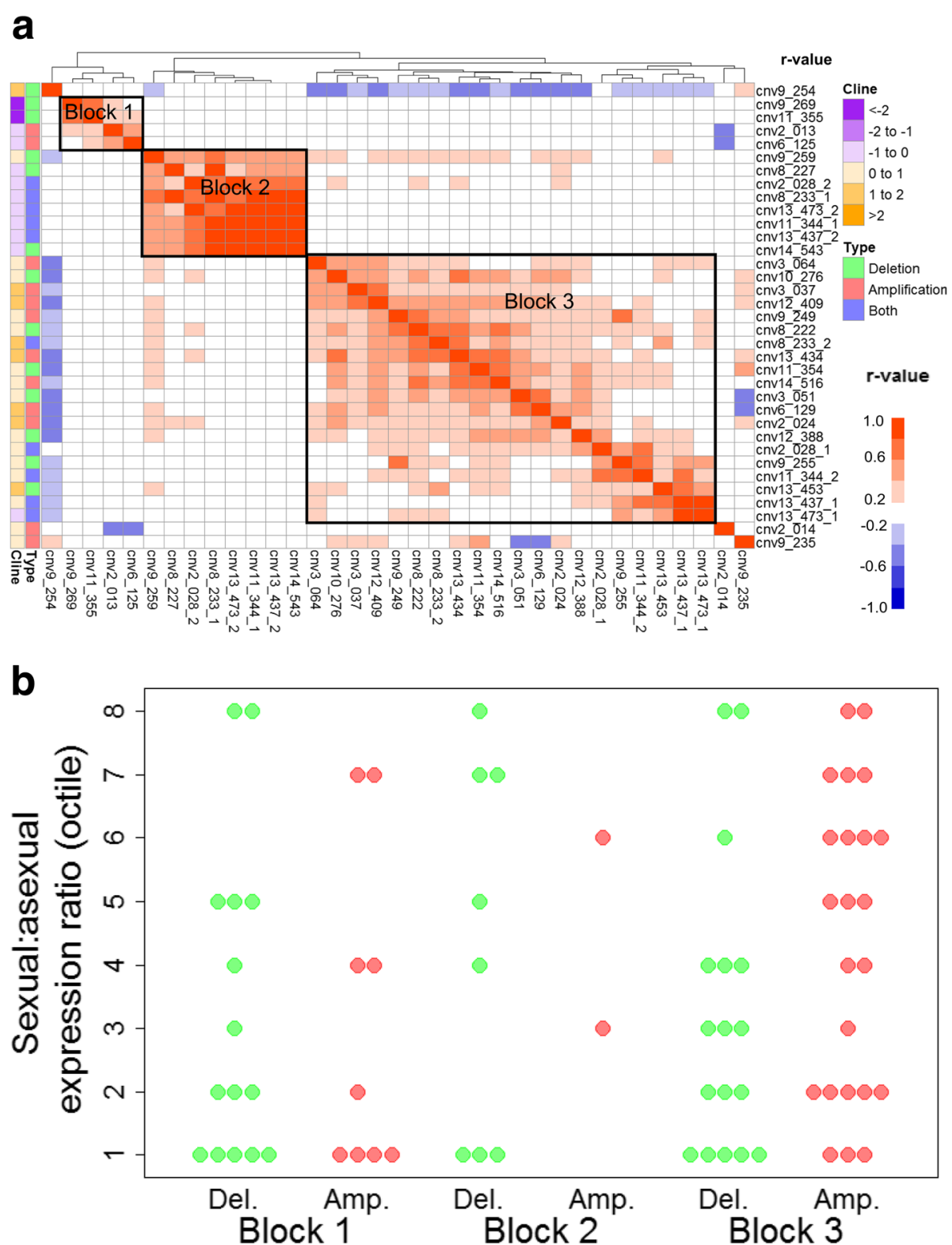

Fig. 4 Associations between CNVs and sexual stage function. a pairwise linkage disequilibrium between CNV alleles. Heatmap colours indicate the strength and direction of the correlation between isolates across populations (r-value, white indicates the same CNV). Colour bars on left indicate the type of CNV and the strength and direction of its transmission intensity related frequency clines. CNVs were clustered (top dendrogram) by similarity in correlation profiles. CNVs with low linkage disequilibria are excluded. $\mathbf{b}$ Ratio of sexual to asexual stage expression (y-axis) for individual inside the genes in (a) grouped by linkage disequilibrium block and CNV type (Amp., amplification; Del., deletion)

liver stage infection [51]. Other genes contained within Block 1 amplification CNVs included the liver stage merozoite protein, PALM, the eukaryotic translation elongation factor EF-G, and geranylgeranyltransferase, all of which are highly expressed during the asexual blood or liver stages. Thus it appears that Block 1 amplifications are associated with functions relating to in vivo asexual replication and survival, including cytoadherence, while Block 1 deletions are associated with loss of sexual function, though also some components of cytoadherence.
Both of the amplification CNVs in Block 1 (cnv2_013 and cnv6_125) showed a strong negative correlation with the CNV directly adjacent to cnv2_013, namely, cnv2 014. cnv2_014, also an amplification, contains two genes which are both abundantly expressed in gametocytes and ookinetes [28]. One of these genes encodes a protein found in the parasite surface membrane (ETRAMP2) which is expressed in mosquito stages, including sporozoites [52], and for which other family members [53], but not this [54], are essential for liver stage 
development in the rodent malaria parasite, $P$. berghei. This apparent antagonism between cnv2_014 and Block 1 amplifications bolsters support for our proposition that Block 1 CNVs create loss of sexual function and concomitant gain in asexual function.

An unexpectedly high proportion of amp-del CNVs were among those showing strong population-level associations (10 of all 10 amp-dels vs. 13 of 31 deletions and 12 of 58 amplifications, $P<0.001$ by Fisher's Exact test). The amp-dels fell mainly within Blocks 2 and 3, and clustered with amplification CNVs. We propose that amp-del CNVs alter their copy number negatively or positively to suit the prevailing functional needs of asexual vs. sexual parasites, as driven by CNVs in Block 1 and Block 3.

We interpret the associations between sets of CNVs in population prevalence as the outcome of co-selection on reproductive vs. replicative investment which differs according to local transmission intensity. In a parallel study on gene expression levels, we have shown that parasites in low transmission areas invest more in reproduction and less in asexual replication than parasites from high transmission areas [55]. We cannot say which environmental factors wield the strongest selective forces, but the most likely candidates are average infection intensities (and hence in-host competition levels), levels of host population immunity, host genetics, drug treatment and transmission opportunities, all of which vary widely between geographical areas and lead to different benefit cost-ratios of reproduction and replication [4]. Alternatively, it is possible that associations between CNV subsets are generated by an over-arching mechanism that coordinates the spontaneous induction of sets of functionally related CNVs. This seems less likely, but not impossible since some strongly correlated CNVs lie adjacent to each other on the chromosome. In particular, CNVs on chromosome 9 were influential and antagonistic, perhaps suggesting that they arise through remodeling of this chromosome at the time of switching from asexual replication to sexual reproduction.

\section{Conclusions}

The results of this study show that gene copy number variation is common in natural populations of $P$. falciparum parasites, consistent with previous studies. They also provide, for the first time, evidence that CNVs in Plasmodium provide adaptive value in the face of natural selection pressures in the parasite's field environment. This evidence is based on observations of more than expected CNVs which display transmission intensityrelated population differentiation, of strong populationlevel associations between CNVs, and that these CNVs contain genes which directly affect short-term in-host fitness (replication) and longer term between-host fitness (reproduction).
We interpret population differences in frequencies of CNVs as the product of three components, namely, the inherent trade-off between asexual replication and reproduction in the parasite's life cycle; the conflict between short-term (in-host) and long-term (betweenhost) fitness; and the different benefit-cost ratios of these fitness components in different transmission environments. For example, in the case of cnv9_269, the sacrifice of gametocyte production incurs little cost in environments with few mosquitoes, thus allowing shortterm selection that favours asexual replication to dominate over longer term selection for transmission to new hosts. Our finding that CNVs cluster according to reproductive vs. replicative functions, and that there are antagonistic associations among deletions that are expected to nullify these functions, suggests that the shortterm selection argument generalizes to other CNVs too, generating co-selected suites of CNVs specialized for these two highly differentiated life stages.

It is difficult to explain how CNVs that cause loss of function are maintained in the general population in the field. We have proposed that this could be achieved through maintenance of genomic fragility at CNV loci that would allow 'bet-hedging' within an infection. Under this strategy, the parasite would divide its asexually replicating lineages into mutant and non-mutant types, thereby allowing maintenance of both asexual replication and reproduction and thus carryover to the next generation. Splitting of function in this way is akin to somatic differentiation of tissues in multi-cellular organisms which allows a balance between growth and reproduction to be achieved in order to maximize lifetime fitness. However, in Plasmodium, it is fitness of the individual parasite, not the population of parasites within the infection, which is rewarded. Although kin selection has been proposed to play a role in the evolution of life history traits in Plasmodium [56], there are few empirical studies to test this. Moreover, it is clear that competition between different genotypes occupying the same host is a strong determinant of the fitness of individual parasite genotypes [57]. This leads us to conclude that CNVs that abrogate sexual function are likely to be the outcome of short-term selection only in the limited situation where infections are clonal and when opportunities for transmission are extremely low. By contrast, we interpret the finding of CNVs associated with enhanced reproductive function as the outcome of selection for between-host transmission when there are regular transmission opportunities and the benefits of switching to reproduction outweigh the costs of reduced asexual replication [41, 58].

This study has some limitations. First, although high stringency was applied in defining CNVs (this by applying high thresholds for significance, filtering out probes 
targeting highly polymorphic genes, probes with known SNPs within the probe sequences, poorly hybridizing probes and low frequency $\mathrm{CNVs}$ ), it cannot be ruled out that unaccounted for DNA sequence variation in the field isolates caused poor probe hybridization thereby leading to false CNVs. Studies of probe hybridization as a function of number of base pair differences between probe and target suggest that 7 out of the 70 bases would have to be different in order to cause nonhybridisation [59]. Second, CNVs in the reference parasite (P4) genome may have led to an over- or underestimation of CNV prevalence. To account for this, we reported $\mathrm{CNV}$ frequencies with respect to the allele with the minor frequency. Third, microarray data provide low resolution of CNV breakpoints, leading to potentially incorrect start and endpoints of a CNV and hence lower accuracy of detection. Finally, choice of reference material, statistical methods, power, significance thresholds, platforms and technologies all differ widely between studies, thus eroding comparability across studies, especially for CNVs not validated through other methods. Although the chromosome 9 deletion is well validated by a variety of detection technologies, including the array used here [18], it is important that the novel finding in this study of its presence in field populations is tested through independent investigations.

Overall, this study shows that CNVs contribute substantially to levels of standing genetic variation in P. falciparum in natural populations and provides multiple lines of evidence that some of these CNVs are adaptive in the face of geographic and temporal variation in the parasite's transmission environment. Further investigation of CNV genes in relation to gene expression levels, of their broader phenotypes, and of the specific selection pressures that mould their population frequencies will provide new leads on molecular mechanisms that allow malaria parasites to survive and adapt, ultimately leading to new ways to control malaria.

\section{Methods}

\section{Sample population}

Parasites were obtained by venesection of $<3 \mathrm{ml}$ of blood from patients diagnosed with $P$. falciparum malaria by microscopy that attended healthcare facilities with symptoms. They were recruited from three areas in Eastern Africa, namely, eastern Sudan (Gedaref, Kassab, Medani, recruited in October 2007), western Kenya (Kisumu, recruited in April-May 2008) and coastal Kenya (Kilifi, recruited in April-May 2010). These areas have maintained low, high and moderate malaria transmission intensities, respectively, over a long period [55]. In Kilifi, archived parasite samples collected from patients recruited from the hospital 15 years previously (1994 to 1996), when transmission intensity was much higher than in 2010 [60], were also analysed: this gave a further contrast of medium-high ("Kilifi-pre") vs. medium-low ("Kilifi-post") transmission populations.

\section{Sample processing}

After centrifugation, the plasma and buffy coat were removed in order to minimize contaminating human host DNA. For samples from Kilifi, 30-200 $\mu$ l of parasiteinfected red blood cells (iRBCs) were stored frozen then thawed on ice and saponified in order to remove intact parasites from RBCs. From this lysate, genomic DNA was extracted using the phenol chloroform method. For samples from Sudan and Kisumu, DNA was extracted from $100 \mu \mathrm{l}$ of iRBCs, which had been stored frozen, using the automated ABI PRISM 6100 Nucleic Acid PrepStation (Applied Biosystems). The number of parasite clones in an isolate was determined by genotyping $P$. falciparum merozoite surface antigen 2 (msp2) gene [61].

\section{Comparative genomic hybridization}

The microarray used for this study consisted of 70mer oligonucleotides (probes) spotted on a glass slide [59]. The probes on the array were designed using the available complete $P$. falciparum genome sequence of 3D7 parasite line [62] targeting conserved regions of approximately 5400 genes with an average of two probes per gene [59]. This array has been previously validated for detection of CNVs [18, 63]. Comparative genomic hybridization $(\mathrm{CGH})$ was performed on 183 samples using as a reference the laboratory culture-adapted line, $\mathrm{P} 4$, that originated from a malaria patient at the Kilifi District Hospital [18]. To increase the amount of DNA available for hybridization to the array, whole genome amplification using random nonamers was performed [64]. Samples were randomized across population groups during amplification and hybridization experiments to avoid batch-of-processing bias. Cyanine fluorescent dyes (Cy3 for reference DNA and Cy5 for test DNA) were used for DNA labelling using the Klenow fragment. PCR amplification was terminated after 19 cycles (during the linear phase) in order to preserve the starting values of relative DNA abundance per gene. Competitive hybridization of each of the test samples against the reference was performed on a MAUI 12-bay hybridization station (BioMicro Systems). Microarray slides were scanned and analysed using GenePix 4000B microarray scanner and its software (version 4.0).

\section{Pre-processing of microarray data}

Analysis of the microarray data was performed using the limma package in $\mathrm{R}$ [65]. First, poor quality spots (less than 6 pixels, or with size that greatly differed from that in the GAL file) were filtered out of the data. Second, data were normalised for spot intensity within arrays 
using the 'normexp' [66] and 'robustspline' [67] methods. Third, data were normalized for between-array variation using the "quantile" method. Data from genes encoding the variant antigen gene families of var., rifin and stevor, and other multi-copy or highly variable genes, ribosomal RNAs and transfer RNAs were excluded from further analyses.

\section{Detection of gene copy number variation using R-GADA}

Genomic regions that varied in copy number were identified using the Genome Alteration Detection Analysis (GADA) program in R [68]. The GADA method identifies contiguous segments in the genome in which $\log _{2}$ intensity differs from that of flanking genes. 'Significant' segments were declared based on a t-statistic calculated from the mean and variance of all the segments (' $T$ ') after applying segmentation analysis with segment length being controlled by the parameter $\mathrm{a}_{\alpha}$. Here, we used the recommended thresholds for high sensitivity but also high false discovery rate of $T=3.5$ and $\mathrm{a}_{\alpha}$ [69]. To reduce false discovery rates, we filtered out segments with less than two microarray probes within the segment and an absolute amplitude of $\log _{2}$ ratio of $<1 \quad(<2$-fold change in gene copy number). Since GADA CNV breakpoint predictions are not precise, and breakpoints also can vary between samples for biological reasons, locations of the start and end points of segments varied between samples. Therefore, segments with overlapping locations across samples and of similar types (i.e., amplification vs. deletion) were merged into a single CNV: this further protected against false discoveries. Finally, CNVs found in less than 4 out of 183 isolates were excluded from the final list of CNVs used in subsequent analyses.

\section{Systematic effects of experimental, host and gene factors} Population prevalence of each $\mathrm{CNV}$ - where population is defined as number of hosts as compared with number of distinct parasite genomes - was analysed as a binary variable (present vs. absent) for the systematic effects of population, multiplicity of infection (MOI), haemoglobin, age of participant, parasitaemia, experimental batch and parasite isolate using mixed effects logistic regression models in the lme4 package in R [70]. All effects were fitted as fixed-level factors with the exception of batch and isolate which were fitted as random effects, the latter to allow for repeated measures on the same parasite material. The same model was fitted to data from all CNVs simultaneously but with further inclusion of CNV identifier as a random effect: this was to test for generalized bias from the above factors in overall $\mathrm{CNV}$ detectability while accounting for repeated measures on the same CNV. Significance of fixed effects was assessed by analysis-of-variance F-tests.
Prevalence of CNVs in the genome was analysed for the systematic effects of the following gene properties: SNP density (obtained from PlasmoDB), ratio of expression during the sexual vs. asexual stages of the life cycle (obtained from [71]), and the stage during the $48 \mathrm{~h}$ asexual replication cycle at which it was maximally expressed (based on data in [55]). A logistic regression model was fitted to the binary variable of whether the gene was a member of a CNV or not fitting fixed effects for fixedlevel factors for the gene property traits above. Analyses were performed separately for CNVs that were deletions vs. amplifications: CNVs exhibiting both of these were ignored. Significance was assessed by analysis-ofdeviance likelihood ratio tests. For all models, leastsquares means were calculated for each level of the fixed effects using the lsmeans package in $\mathrm{R}$ [72].

\section{Functional enrichment}

Enrichment for function among genes identified to be copy number variable was assessed by hypergeometric test for over-representation of CNVs among sets of functionally related genes, implemented by using the 'phyper' function in the stats package in R [73] and corrected for multiple testing using the Benjamini-Hochberg method [74]. Gene sets were constructed from the Malaria Parasite Metabolic Pathways database [75] and further categorized into higher level functional groupings as described in [55].

\section{Testing for evidence of population-level adaptation}

To test for evidence of CNV-related population level adaptation in general, Weir and Cockerham F-statistics $\left(\mathrm{F}_{\mathrm{ST}}\right)$ for levels of between-to-within population variation in allele frequencies were calculated for each $\mathrm{CNV}$ using hierfstat as implemented in R [76]. CNVs with unusually high or low values, and thus potential targets of directional and diversifying selection, respectively, were identified by comparing them to the distribution of $\mathrm{F}_{\mathrm{ST}}$ values for all CNVs. To determine whether these population differences were related to transmission intensity in the population, a fixed effects logistic regression model was fitted to prevalence data for each $\mathrm{CNV}$ with population fitted as a linear covariate representing the populations' ranks in transmission intensity, i.e., 1 to 4 for Sudan, Kilifi-post, Kilifi-pre and Kisumu respectively. This model was fitted to data on all CNVs simultaneously, with CNV fitted as a fixed effect and the population covariate fitted within CNV. The standardized regression slopes (z-score) for each $\mathrm{CNV}$, which represent the cline in $\mathrm{CNV}$ frequency across the transmission intensity gradient, were compared to a null distribution of slopes constructed by fitting the same model to 1000 permutations of the data in which population membership of each parasite isolate had been randomly 
reassigned. Unadjusted $P$-values for regression slopes were based on t-tests using the error variance from all CNVs combined. To allow for multiple testing, P-values were adjusted to reflect a false discovery rate using the Benjamini-Hochberg method [74].To test whether the observed distribution of slopes for all the CNVs differed from that expected by chance, a global test statistic, namely, the sum of the absolute z-scores, was computed for the observed data and compared to the distribution of this statistic from the permuted data. CNVs with significant clines (adjusted $P<0.05$ ) or $\mathrm{F}_{\mathrm{ST}}$ values $>0.3$ for at least one of their pairwise population values were defined as 'adaptive'.

\section{Linkage disequilibrium}

To test for population level associations between CNVs, linkage disequilibria between all pairwise combinations of CNVs were calculated using the pegas package in $\mathrm{R}$ [77]. Pearson correlations were computed between frequencies of the CNVs' minor alleles (r-values). CNVs with both amplification and deletion alleles were treated separately. Results were visualized as a heatmap using the pheatmap package in $\mathrm{R}$.

\section{Additional file}

Additional file 1: CNVs found in this study and their characteristics. Names of CNVs, their type (amplification or deletion), the genes contained within them and previous reports in the literature. (PDF $175 \mathrm{~kb}$ )

\section{Abbreviation}

CNV: Copy number variant

\section{Acknowledgements}

We are grateful to the study participants and to M Alfaki, A Abdullah, I ElHassan, J Musyoki, M Mosobo and M Opiyo for assistance with collection and processing of the blood samples.

\section{Funding}

This work was supported by The Wellcome Trust (grant numbers 088634 to MJM, 092741 and 077176 to KM). The funder was not involved in the design of the study and collection, analysis, and interpretation of data and in writing the manuscript.

\section{Availability of data and materials}

The processed data supporting the conclusions of this article are included within the article and in Additional file 1. The raw data are available in the Gene Expression Omnibus (GEO) repository (accession number GSE113087).

\section{Authors' contributions}

MM collected the samples. JS, JM, MN and MR performed the microarray assays. ZB and SM provided the microarrays. JS and MM analysed the data. MM designed the study with contributions from ZB and KM. JS and MM drafted the manuscript. All authors read and approved the final manuscript.

\section{Ethics approval and consent to participate}

Ethical approval for the study was obtained from the Kenyan National Ethical Review Committee (SCC 1292) and the Sudan National Ethical Review Committee. Written consent was obtained from parents or guardians of the study participants $<14$ years of age, or the participants themselves otherwise. This paper is published with the permission of the Director of KEMRI.

\section{Competing interests}

The authors declare that they have no competing interests.

\section{Publisher's Note}

Springer Nature remains neutral with regard to jurisdictional claims in published maps and institutional affiliations.

\section{Author details}

${ }^{1}$ KEMRI-Wellcome Trust Research Program, Kilifi, Kenya. ${ }^{2}$ Department of Microbiology and Molecular Medicine, Medical Faculty, University of Geneva, Geneva, Switzerland. ${ }^{3}$ Department of Microbiology and Immunology, Columbia University, New York, USA. ${ }^{4}$ Centre for Tropical Medicine and Global Health, Nuffield Department of Clinical Medicine, University of Oxford, Oxford, UK. ${ }^{5}$ School of Biological Sciences, Nanyang Technological University, Singapore, Singapore. ${ }^{6}$ http://www.researcherid.com/rid/L-3155-2013. ${ }^{7}$ Independent Researcher, Nairobi, Kenya. ${ }^{8}$ Pwani University Bioscience Research Centre, Pwani University, Kilifi, Kenya.

Received: 20 September 2017 Accepted: 17 April 2018

Published online: 21 May 2018

\section{References}

1. Volkman SK, Sabeti PC, DeCaprio D, Neafsey DE, Schaffner SF, Milner DA Jr, Daily JP, Sarr O, Ndiaye D, Ndir O, et al. A genome-wide map of diversity in Plasmodium falciparum. Nat Genet. 2007;39:113-9.

2. Jeffares DC, Pain A, Berry A, Cox AV, Stalker J, Ingle CE, Thomas A, Quail MA, Siebenthall K, Uhlemann AC, et al. Genome variation and evolution of the malaria parasite Plasmodium falciparum. Nat Genet. 2007;39:120-5.

3. Soulama I, Bigoga JD, Ndiaye M, Bougouma EC, Quagraine J, Casimiro PN, Stedman TT, Sirima SB. Genetic diversity of polymorphic vaccine candidate antigens (apical membrane antigen-1, merozoite surface protein-3, and erythrocyte binding antigen-175) in Plasmodium falciparum isolates from western and Central Africa. Am J Trop Med Hyg. 2011;84:276-84.

4. Mackinnon MJ, Marsh K. The selection landscape of malaria parasites. Science. 2010;328:866-71.

5. Kleinjan DA, van Heyningen V. Long-range control of gene expression: emerging mechanisms and disruption in disease. Am J Hum Genet. 2005;76:8-32.

6. Henrichsen CN, Chaignat E, Reymond A. Copy number variants, diseases and gene expression. Hum Mol Genet. 2009;18:R1-8.

7. Tam GW, Redon R, Carter NP, Grant SG. The role of DNA copy number variation in schizophrenia. Biol Psychiatry. 2009;66:1005-12.

8. Angstadt AY, Berg A, Zhu J, Miller P, Hartman TJ, Lesko SM, Muscat JE, Lazarus $P$, Gallagher $C$. The effect of copy number variation in the phase II detoxification genes UGT2B17 and UGT2B28 on colorectal cancer risk. Cancer. 2013;119:2477-85.

9. Wellcome Trust Case Control C, Craddock N, Hurles ME, Cardin N, Pearson RD, Plagnol V, Robson S, Vukcevic D, Barnes C, Conrad DF, et al. Genomewide association study of CNVs in 16,000 cases of eight common diseases and 3,000 shared controls. Nature. 2010;464:713-20.

10. Li W, Olivier M. Current analysis platforms and methods for detecting copy number variation. Physiol Genomics. 2013;45:1-16.

11. Cheeseman IH, Gomez-Escobar N, Carret CK, Ivens A, Stewart LB, Tetteh KK, Conway DJ. Gene copy number variation throughout the Plasmodium falciparum genome. BMC Genomics. 2009;10:353.

12. Kidgell C, Volkman SK, Daily JP, Borevitz JO, Plouffe D, Zhou Y, Johnson JR Le Roch KG, Sarr O, Ndir O, et al. A systematic map of genetic variation in Plasmodium falciparum. PLoS Pathog. 2006;2:e57.

13. Dharia NV, Sidhu AB, Cassera MB, Westenberger SJ, Bopp SE, Eastman RT, Plouffe D, Batalov S, Park DJ, Volkman SK, et al. Use of high-density tiling microarrays to identify mutations globally and elucidate mechanisms of drug resistance in Plasmodium falciparum. Genome Biol. 2009;10:R21.

14. Jiang $H$, Yi M, Mu J, Zhang L, Ivens A, Klimczak LJ, Huyen Y, Stephens RM, Su XZ. Detection of genome-wide polymorphisms in the AT-rich Plasmodium falciparum genome using a high-density microarray. BMC Genomics. 2008;9:398.

15. Carret CK, Horrocks P, Konfortov B, Winzeler EA, Qureshi M, Newbold Cl, Ivens A. Microarray-based comparative genomic analyses of the human malaria parasite Plasmodium falciparum using Affymetrix arrays. Mol Biochem Parasitol. 2005;144:177-86. 
16. Ribacke U, Mok BW, Wirta V, Normark J, Lundeberg J, Kironde F, Egwang TG, Nilsson P, Wahlgren M. Genome wide gene amplifications and deletions in Plasmodium falciparum. Mol Biochem Parasitol. 2007;155:33-44.

17. Samarakoon U, Gonzales JM, Patel JJ, Tan A, Checkley L, Ferdig MT. The landscape of inherited and de novo copy number variants in a Plasmodium falciparum genetic cross. BMC Genomics. 2011;12:457.

18. Mackinnon MJ, Li J, Mok S, Kortok MM, Marsh K, Preiser PR, Bozdech Z. Comparative transcriptional and genomic analysis of Plasmodium falciparum field isolates. PLoS Pathog. 2009;5:e1000644.

19. Kemp DJ, Thompson J, Barnes DA, Triglia T, Karamalis F, Petersen C, Brown GV, Day KP. A chromosome 9 deletion in Plasmodium falciparum results in loss of cytoadherence. Mem Inst Oswaldo Cruz. 1992;87(Suppl 3):85-9.

20. Alano P, Roca L, Smith D, Read D, Carter R, Day K. Plasmodium falciparum: parasites defective in early stages of gametocytogenesis. Exp Parasitol. 1995; 81:227-35.

21. Biggs BA, Kemp DJ, Brown GV. Subtelomeric chromosome deletions in field isolates of Plasmodium falciparum and their relationship to loss of cytoadherence in vitro. Proc Natl Acad Sci U S A. 1989;86:2428-32.

22. Nair S, Nkhoma S, Nosten F, Mayxay M, French N, Whitworth J, Anderson T. Genetic changes during laboratory propagation: copy number at the reticulocyte-binding protein 1 locus of Plasmodium falciparum. Mol Biochem Parasitol. 2010;172:145-8.

23. Triglia T, Duraisingh MT, Good RT, Cowman AF. Reticulocyte-binding protein homologue 1 is required for sialic acid-dependent invasion into human erythrocytes by Plasmodium falciparum. Mol Microbiol. 2005;55:162-74.

24. Koenderink JB, Kavishe RA, Rijpma SR, Russel FG. The ABCs of multidrug resistance in malaria. Trends Parasitol. 2010:26:440-6.

25. Ariey F, Witkowski B, Amaratunga C, Beghain J, Langlois AC, Khim N, Kim S, Duru V, Bouchier C, Ma L, et al. A molecular marker of artemisinin-resistant Plasmodium falciparum malaria. Nature. 2014;505:50-5.

26. Singh A, Rosenthal PJ. Selection of cysteine protease inhibitor-resistant malaria parasites is accompanied by amplification of falcipain genes and alteration in inhibitor transport. J Biol Chem. 2004;279:35236-41.

27. Klonis N, Crespo-Ortiz MP, Bottova I, Abu-Bakar N, Kenny S, Rosenthal PJ, Tilley L. Artemisinin activity against Plasmodium falciparum requires hemoglobin uptake and digestion. Proc Natl Acad Sci U S A. 2011;108:11405-10.

28. Jiang H, Patel JL, Yi M, Mu J, Ding J, Stephens R, Cooper RA, Ferdig MT, Su X. Genome-wide compensatory changes accompany drugselected mutations in the Plasmodium falciparum crt gene. PLoS One. 2008:3:e2484.

29. Cheeseman IH, Miller B, Tan JC, Tan A, Nair S, Nkhoma SC, De Donato M, Rodulfo H, Dondorp A, Branch OH, et al. Population structure shapes copy number variation in malaria parasites. Mol Biol Evol. 2016;33:603-20.

30. Picot S, Olliaro P, de Monbrison F, Bienvenu AL, Price RN, Ringwald P. A systematic review and meta-analysis of evidence for correlation between molecular markers of parasite resistance and treatment outcome in falciparum malaria. Malar J. 2009;8:89.

31. Nair S, Miller B, Barends M, Jaidee A, Patel J, Mayxay M, Newton P, Nosten F, Ferdig MT, Anderson TJ. Adaptive copy number evolution in malaria parasites. PLoS Gen. 2008;4:e1000243.

32. Heinberg A, Siu E, Stern C, Lawrence EA, Ferdig MT, Deitsch KW Kirkman LA. Direct evidence for the adaptive role of copy number variation on antifolate susceptibility in Plasmodium falciparum. Mol Microbiol. 2013;88:702-12.

33. Mobegi VA, Loua KM, Ahouidi AD, Satoguina J, Nwakanma DC, AmambuaNgwa A, Conway DJ. Population genetic structure of Plasmodium falciparum across a region of diverse endemicity in West Africa. Malar J. 2012;11:223.

34. Shirley MW, Biggs BA, Forsyth KP, Brown HJ, Thompson JK, Brown GV, Kemp DJ. Chromosome 9 from independent clones and isolates of Plasmodium falciparum undergoes subtelomeric deletions with similar breakpoints in vitro. Mol Biochem Parasitol. 1990;40:137-45.

35. Hancock AM, Witonsky DB, Alkorta-Aranburu G, Beall CM, Gebremedhin A, Sukernik R, Utermann G, Pritchard JK, Coop G, Di Rienzo A. Adaptations to climate-mediated selective pressures in humans. PLoS Genet. 2011;7:e1001375.

36. Bersaglieri T, Sabeti PC, Patterson N, Vanderploeg T, Schaffner SF, Drake JA, Rhodes M, Reich DE, Hirschhorn JN. Genetic signatures of strong recent positive selection at the lactase gene. Am J Hum Genet. 2004;74:1111-20.

37. Mackinnon MJ, Ndila C, Uyoga S, Macharia A, Snow RW, Band G, Rautanen A, Rockett KA, Kwiatkowski DP, Williams TN. Environmental correlation analysis for genes associated with protection against malaria. Mol Biol Evol. 2016;33:1188-204
38. Eksi S, Morahan BJ, Haile Y, Furuya T, Jiang H, Ali O, Xu H, Kiattibutr K, Suri A, Czesny $B$, et al. Plasmodium falciparum gametocyte development 1 (Pfgdv1) and gametocytogenesis early gene identification and commitment to sexual development. PLoS Pathog. 2012;8:e1002964.

39. Gardiner DL, Dixon MW, Spielmann T, Skinner-Adams TS, Hawthorne PL, Ortega MR, Kemp DJ, Trenholme KR. Implication of a Plasmodium falciparum gene in the switch between asexual reproduction and gametocytogenesis. Mol Biochem Parasitol. 2005;140:153-60.

40. Bourke PF, Holt DC, Sutherland CJ, Kemp DJ. Disruption of a novel open reading frame of Plasmodium falciparum chromosome 9 by subtelomeric and internal deletions can lead to loss or maintenance of cytoadherence. Mol Biochem Parasitol. 1996;82:25-36.

41. Greischar MA, Mideo N, Read AF, Bjornstad ON. Predicting optimal transmission investment in malaria parasites. Evolution. 2016;70:1542-58.

42. Levin BR, Bull JJ. Short-sighted evolution and the virulence of pathogenic microorganisms. Trends Microbiol. 1994;2:76-81.

43. Read AF, Narara A, Nee S, Keymer AE, Day KP. Gametocyte sex ratios as indirect measures of outcrossing rates in malaria. Parasitology. 1992; 104(Pt 3):387-95.

44. Mobegi VA, Duffy CW, Amambua-Ngwa A, Loua KM, Laman E, Nwakanma DC, Maclnnis B, Aspeling-Jones H, Murray L, Clark TG, et al. Genome-wide analysis of selection on the malaria parasite Plasmodium falciparum in west African populations of differing infection endemicity. Mol Biol Evol. 2014;31:1490-9.

45. Rono MK, Nyonda MA, Simam JJ, Ngoi JM, Mok S, Kortok MM, Abdullah AS, Elfaki MM, Waitumbi JN, El-Hassan IM, et al. Adaptation of Plasmodium falciparum to its transmission environment. Nat Ecol Evol. 2018;2:377-87.

46. Lang-Unnasch N, Murphy AD. Metabolic changes of the malaria parasite during the transition from the human to the mosquito host. Annu Rev Microbiol. 1998;52:561-90

47. MacRae Jl, Dixon MW, Dearnley MK, Chua HH, Chambers JM, Kenny S, Bottova I, Tilley L, McConville MJ. Mitochondrial metabolism of sexual and asexual blood stages of the malaria parasite Plasmodium falciparum. BMC Biol. 2013;11:67.

48. Mattei D, Scherf A. The Pf332 gene of Plasmodium falciparum codes for a giant protein that is translocated from the parasite to the membrane of infected erythrocytes. Gene. 1992;110:71-9.

49. Rug M, Prescott SW, Fernandez KM, Cooke BM, Cowman AF. The role of KAHRP domains in knob formation and cytoadherence of $P$ falciparuminfected human erythrocytes. Blood. 2006;108:370-8.

50. Rug M, Cyrklaff M, Mikkonen A, Lemgruber L, Kuelzer S, Sanchez CP, Thompson J, Hanssen E, O'Neill M, Langer $C$, et al. Export of virulence proteins by malaria-infected erythrocytes involves remodeling of host actin cytoskeleton. Blood. 2014;124:3459-68.

51. Siau A, Silvie O, Franetich JF, Yalaoui S, Marinach C, Hannoun L, van Gemert GJ, Luty AJ, Bischoff E, David PH, et al. Temperature shift and host cell contact upregulate sporozoite expression of Plasmodium falciparum genes involved in hepatocyte infection. PLoS Pathog. 2008:4:e1000121.

52. Curra C, Di Luca M, Picci L, de Sousa Silva Gomes dos Santos C, SidenKiamos I, Pace T, Ponzi M. The ETRAMP family member SEP2 is expressed throughout Plasmodium berghei life cycle and is released during sporozoite gliding motility. PLoS One. 2013;8:e67238.

53. Mackellar DC, O'Neill MT, Aly AS, Sacci JB Jr, Cowman AF, Kappe SH. Plasmodium falciparum PF10_0164 (ETRAMP10.3) is an essential parasitophorous vacuole and exported protein in blood stages. Eukaryot Cell. 2010;9:784-94.

54. Mackellar DC, Vaughan AM, Aly AS, De Leon S, Kappe SH. A systematic analysis of the early transcribed membrane protein family throughout the life cycle of Plasmodium yoelii. Cell Microbiol. 2011;13:1755-67.

55. Rono MK, Nyonda MA, Simam JJ, Ngoi JM, Mok S, Abdullah SA, Elfaki MM, Waitumbi JN, Elhassan IM, Marsh K, et al. Adaptation of Plasmodium falciparum to its transmission environment. Nat Ecol Evol. 2008;2(2):377-87.

56. Read AF, Mackinnon MJ, Anwar MA, Taylor LH. Kin selection models as evolutionary explanations of malaria. In: Dieckmann U, Metz JAJ, Sabelis MW, Sigmund K, editors. Virulence management: the adaptive dynamics of pathogenhost interactions. Cambridge: Cambridge University Press; 2002. p. 165-78.

57. Frevert U, Sinnis P, Cerami C, Shreffler W, Takacs B, Nussenzweig V. Malaria circumsporozoite protein binds to heparan sulfate proteoglycans associated with the surface membrane of hepatocytes. J Exp Med. 1993;177:1287-98.

58. Reece SE, Ramiro RS, Nussey DH. Plastic parasites: sophisticated strategies for survival and reproduction? Evol Appl. 2009;2:11-23. 
59. Bozdech Z, Zhu JC, Joachimiak MP, Cohen FE, Pulliam BL, DeRisi JL. Expression profiling of the schizont and trophozoite stages of Plasmodium falciparum with a long-oligonucleotide microarray. Genome Biol. 2003:4:R9.1-R9.14.

60. O'Meara WP, Bejon P, Mwangi TW, Okiro EA, Peshu N, Snow RW, Newton $\mathrm{CR}$, Marsh K. Effect of a fall in malaria transmission on morbidity and mortality in Kilifi, Kenya. Lancet. 2008;372:1555-62.

61. Liljander A, Wiklund L, Falk N, Kweku M, Martensson A, Felger I, Farnert A. Optimization and validation of multi-coloured capillary electrophoresis for genotyping of Plasmodium falciparum merozoite surface proteins (msp1 and 2). Malar J. 2009;8:78.

62. Gardner MJ, Hall N, Fung E, White O, Berriman M, Hyman R, Carlton JMR, Pain A, Nelson K, Bowman S, et al. Genome sequence of the human malaria parasite Plasmodium falciparum. Nature. 2002:419:498-511.

63. Llinas M, Bozdech Z, Wong ED, Adai AT, DeRisi JL. Comparative whole genome transcriptome analysis of three Plasmodium falciparum strains. Nucleic Acids Res. 2006;34:1166-73.

64. Petalidis L, Bhattacharyya S, Morris GA, Collins VP, Freeman TC, Lyons PA Global amplification of mRNA by template-switching PCR: linearity and application microarray analysis. Nucleic Acids Res. 2003;31:e142.

65. Smyth GK. Limma: linear models for microarray data. In: Gentleman R, Carey V, Dudoit S, Irizarry R, Huber W, editors. Bioinformatics and computational biology solutions using $\mathrm{R}$ and Bioconductor. New York: Springer; 2005. p. 397-420.

66. Ritchie ME, Silver J, Oshlack A, Holmes M, Diyagama D, Holloway A, Smyth GK. A comparison of background correction methods for two-colour micorarrays. Bioinformatics. 2007;23:2700-7.

67. Smyth GK, Speed TP. Normalization of CDNA microarray data. Methods. 2003;31:265-73.

68. Pique-Regi R, Caceres A, Gonzalez JR. R-Gada: a fast and flexible pipeline for copy number analysis in association studies. BMC Bioinforma. 2010;11:380.

69. Pique-Regi R, Ortega A, Asgharzadeh S. Joint estimation of copy number variation and reference intensities on multiple DNA arrays using GADA. Bioinformatics. 2009;25:1223-30.

70. Bates D, Maechler M, Bolker BM, Walker S. Ime4: linear mixed-effects models using Eigen and S4. J Stat Softw. 2015;67:1-48.

71. Lopez-Barragan MJ, Lemieux J, Quinones M, Williamson KC, Molina-Cruz A, Cui K, Barillas-Mury C, Zhao K, Su XZ. Directional gene expression and antisense transcripts in sexual and asexual stages of Plasmodium falciparum. BMC Genomics. 2011;12:587.

72. Lenth RV. Least-squares means: the R package Ismeans. J Stat Softw. 2016;69:1-33.

73. R Core Team. R: A Language and Environment for Statistical Computing. Foundation for Statistical Computing: R Foundation for Statistical Computing; 2015. http://www.R-project.org/.

74. Benjamini $Y$, Hochberg Y. Controlling the false discovery rate: a practical and powerful approach to multiple testing. J R Stat Soc B. 1995;57:289-300.

75. Malaria Parasite Metabolic Pathways. http://mpmp.huji.ac.il/home. Accessed March 2016.

76. Goudet J. Hierfstat, a package for R to compute and test hierarchical Fstatistics. Mol Ecol Res. 2005;5:184-6.

77. Paradis E. Pegas: an R package for population genetics with an integratedmodular approach. Bioinformatics. 2010;26:419-20,

\section{Ready to submit your research? Choose BMC and benefit from:}

- fast, convenient online submission

- thorough peer review by experienced researchers in your field

- rapid publication on acceptance

- support for research data, including large and complex data types

- gold Open Access which fosters wider collaboration and increased citations

- maximum visibility for your research: over $100 \mathrm{M}$ website views per year

At BMC, research is always in progress.

Learn more biomedcentral.com/submissions 